\title{
A Study on Improving Conventional mix of Flexible Pavement using Additive
}

\author{
Shivani Patel \\ M.E. Transportation Engineer \\ Department of Civil Engineering, \\ L.D. College of Engineering Ahmedabad, India
}

\author{
Dr. V. R. Patel \\ Associate Professor \\ Department of Civil Engineering, \\ L.D. College of Engineering Ahmedabad, India
}

\begin{abstract}
Roads play a major role in the overall infrastructure development of any country. Any kind of deterioration in roadways needs to be restricted, as it directly or indirectly affects the overall growth of our country. With time, due to environmental exposure, bitumen degrades chemically and becomes brittle. In addition, moisture may penetrate in the pavement/road structure, causing loss of adhesion between aggregates and binder. As urbanization takes place we need to improve old techniques of mix to overcome new problems. This paper presents a laboratory study of modified bitumen containing styrene-butadiene-styrene (SBS). A $50 / 70$ penetration grade base (unmodified) bitumen has been mixed with SBS polymer at different proportions, e.g. $2 \%, 3 \%, 4 \%$. The mechanical properties of the hot-mix asphalt (HMA) containing SBS have also been analyzed and compared with HMA incorporating base bitumen. The results indicated that the properties of the polymer modified HMA are dependent on the polymer content. Polymer modification improved the conventional properties of the base bitumen such as; penetration, softening point, temperature susceptibility, etc. It was also concluded that, the mechanical properties of HMA prepared with the SBS samples such as Marshall stability were enhanced with the increasing polymer contents. The main goal of our study is to understand the different properties of material used in the mix and to improve the properties of conventional asphalt mix by adding some admixture.
\end{abstract}

Keywords - Conventional mix of flexible pavement, Performance Evaluation of mix with different quantities of SBS.

\section{INTRODUCTION}

Among the various modes of transport, road transport plays the vital role in economic, social and industrial development of the country. Just like arteries in human being, roads perform the similar function in the transportation of people and goods from one place to another. Before the advent of automobile carts and pedestrians were the main road users, pathways and kachha (Earthen road) roads catered to their needs .but emergence of automobiles and all-round developments the earthen road could not help for the smooth flow of goods and passenger. Hence there was a need arose for all-weather and better surface road so as to provide comfortable and efficient movement of vehicular traffic. If the pavement is not suitably designed and properly constructed it would lead to uneven surface having poor riding quality causing discomfort to passengers. In addition it will increase fuel consumption, wear and tear of vehicle components resulting in overall increased vehicle operation cost. On the other hand pavement design on scientific basis with proper material and adequate thickness provide smooth riding surface and durability apart from providing comfort to the passengers in order to understand the concept of flexible pavement design lets us have a look at the components layers of the pavement structure the different component layers of the flexible pavement comprise sub-grade, sub-base, base course, wearing course, surface seal coat, constructed over a prepared soil layer.

A pavement structure can be designed either as a flexible pavement or a rigid pavement based on its structural behaviour. But flexible pavements are widely preferred in India due to its advantages over rigid pavements and it is comparatively economical. Flexible pavements have low or negligible flexural strength and are rather flexible in their structural action under the loads.

The layered pavement structure transmits vertical or compressive stresses to the lower layers by grain to grain transfer through the points of contact in the granular structure with strong graded aggregates and should transfer the compressive stresses to a wider area. In light of the above factors, it can be learnt that bituminous mix is one of the best flexible pavement layer materials. Bituminous mix is generally used as a surface course and wearing course in flexible pavements since it is necessary that the wearing course must provide a smooth riding surface that is dense and at the same time take up wear and tear due to traffic.

Damage in pavements is a phenomenon that pavement design and maintenance engineers are dealing with for years. There are two main reasons for damage i.e. fatigue cracking and rutting in the pavement. Cracks are unavoidable and if neglected then leads to accelerated cracking and formation of potholes which further reduces the pavement serviceability. The problem of cracks is handled in many ways, ranging from pavement maintenance activities, such as surface treatments and crack filling, to full-scale pavement rehabilitation projects.

Patching is becoming a difficult task as permanent solutions are not available so potholes are needed to be repaired again in short time intervals after patching. Road maintenance agencies are facing the challenge in dealing with these problems. While actual figures are difficult to obtain, it was estimated that a huge amount of money is being spent on pothole patching and maintenance of pavements. Here main focus is to find different additive components to improve the mix rather than spending tons of money over maintenance work. 


\section{LITERARURE REVIEW}

The literature review section discusses the various causes of localized damage to flexible pavements and various methods/materials used for retrofitting it.

Ala R. Abbas et.al (2013) presented an effect of recycled asphalt shingles on physical and chemical properties of virgin asphalt binders. A virgin asphalt binder was mixed with varying percentages $(0 \%, 5 \%, 7 \%$, and 10\%) of RAS.However, significantly higher levels of aging were obtained for PAV-aged binders containing higher percentages of RAS, indicating that the addition of RAS will primarily impact the long term performance of the asphalt binders. The addition of RAS causes the asphalt binder to become stiffer and harder to mix and handle and the addition will also improve the asphalt binder performance in the context of rutting.

Mohd Ezree Abdullah et al. (2016), The objective of this study is to improve the properties of the asphalt binders using the addition of nano-clays and chemical WMA additive. In this study materials used are ,Nano-clay A (montmorillonite clay surface modified with 35-45 wt.\% dimethyl dialkyl (C14-C18)amine, Nano-clay B (montmorillonite clay surface modified with 35-45 wt.\% octadecylamine, and 0.5-5.0 wt.\% aminopropyl-triethoxysilane), and chemical WMA additive (fatty polyamines polymer non-ionic component).An asphalt binder of 80/100 penetration grade was modified with different percentages of Nano-clay A,Nano-clay B and chemical WMA additive. After modification, the asphalt binders were named Nanoclay A modified asphalt binder (NCMB A), Nano-clay B modified asphalt binder (NCMB $\mathrm{B})$, and chemical WMA modified asphalt binder (CWAA), The NCMB A and NCMB B reduced penetration and increased softening point. The modified asphalt binders exhibited significantly higher Surface Free Energy when compared with unmodified asphalt binder and could have good adhesion between aggregates. Therefore, modified asphalt binders could potentially be good at increasing the resistance of asphalt mixes to moisture induced damage. NCMB B4\% could potentially become a new WMA binder in comparison to CWAA.The gap for this particular study is that, availability is not there and cost of nano-clay is almost $14,000 \mathrm{Rs} / \mathrm{Kg}$., which lead to an uneconomical model.

Mahyar Arabani et.al (2017) presented a study on assessment of mechanical properties of rice husk ash modified asphalt mixture.The addition of RHA could improve significantly the rutting resistance of HMAs at different stresses and temperatures that could be attributed to the improvement of rutting parameter and elastic behavior of modified binders. Also, the rutting performance of HMAs with 15\% RHA and 20\% RHA are almost similar According to fatigue test results, mixtures containing RHA exhibited better fatigue life compared to control mixtures. This enhancement might be due to reduction of air void in mixture and/or improvement of adhesion between binder and aggregates. The mixture with $15 \%$ RHA had the highest fatigue life.
Nyoman Arya Thanaya et.al (2014) presented a study on properties of Cold Asphalt Emulsion Mixtures (CAEMs) using materials from old road pavement milling. Cold Asphalt Emulsion Mixtures (CAEMs) can be produced at room temperature which can incorporate milled old road pavement (upto $72.73 \%$ ). Some virgin aggregate and rice husk ash as filler material and cement was added into the mixture.The samples containing ordinary Portland cement (OPC) showed higher stability, as the cement would assist the hardening of the compacted samples. All properties of the CAEMs well meet the specification, further tests like stiffness tests, creep tests, and fatigue tests are necessary, in order to attain a broader appreciation on the performance of CAEMs.

Obaidi et al. (2016) presented a fast pothole repair method using asphalt tiles and induction heating.In this method we are using an asphalt mixture tile with a bottom bonding layer made of bitumen, and steel fibers, exposed to high frequency electromagnetic fields to heat the fibers up and melt the bitumen(modified bitumen with $4 \%$ of SBS) in the bonding layer. Recycled steel fibers from old tyres were used to minimize the environmental impact. The bond between the tile and the old road is created by heating the fibers, by using of induction energy, and applying light compaction. With this technology, in less than 1 min of induction heating, the bonding layer reaches temperatures above $100^{\prime} \mathrm{C}$ and tile and old pavement stick together. The physical principle behind the strength gain of tiles is the drain of bitumen towards the gap between the asphalt tile and block. This was powered by the (1) total pressure exerted over the bonding layer, e.g. by the weight of the tile, (2) viscosity of bitumen and (3) total amount of bitumen available. The rutting deformation of asphalt tiles under simulated traffic conditions was very similar to that of original asphalt mixture and approximately 40 times smaller for the same loading time and energy.

But the gap of this particular is given as following, (1) When we encounter many different size of potholes, it will going to be tedious work to make Asphalt tile every time with different sizes. (2)As we are using here induce heating and for that we are using coil and $6 \mathrm{Kw}$ induction heating generator., which makes it a bulky structure to carry at traffic road site.(3)we cannot use this kind of tile technology in patching work of small potholes or cracks on the flexible road.

Shifeng Wang et.al (2016) presented a study on recent developments in the application of chemical approaches to rubberized asphalt. A binder called Rubberized asphalt which is produced by adding crumb tire rubber modifier into heated asphalt. It shows better cracking resistance and fatigue resistance as compared to conventional asphalt. By adding chemical additives to rubberized asphalt, many improvements like low rutting resistance, high viscosity and poor storage stability are achieved.Degraded tire rubber hybridized with SBS is accepted for its usage in pavements. Inorganic filler can be used to improve rutting resistance and moisture resistance. However, the sediment of filler in the asphalt prevents it from being implemented on a large scale. 
Plasticizer improves process ability but influences high temperature properties. Therefore, different additives must be combined in order to maintain a suitable balance between processing and acceptable physical properties.

Yanping Yin et al. (2017), showed the study on the Effect of chemical composition of aggregate on inter facial adhesion property between aggregate and asphalt. This study compared the inter-facial adhesion properties of asphalt with SBSstone aggregate and asphalt with granite aggregate. The main chemical compositions of SBSstone and granite are $\mathrm{CaCO} 3$ and $\mathrm{SiO} 2$, respectively. The results show that the inter facial adhesion strength of the asphalt with SBSstone aggregate is higher than that of the asphalt with granite aggregate. The main chemical constituent of SBSstone is $\mathrm{CaCO} 3$, and the main chemical constituent of granite is $\mathrm{SiO} 2$. Carbon, oxygen, and sulfur are the main elements of asphalt, and the sulfoxide group has an influence on the adhesion property of asphalt. On the other hand, the adhesion function of the granite aggregate only depends on its physical adhesion with asphalt. In summary we can say that SBS stone aggregate show more adhesion strength with asphalt as compare to the granite aggregate.

\section{A. Conclusions}

This literature search and product review has identified several methods to improve the conventional mix. The review process also showed there are a number of factors that go into choosing which additive will be most suited to a particular situation. The first step in selecting a material is to identify the key properties that a material must possess to be efficiently placed and perform successfully in the conditions provided for the time desired. Several of the more desirable properties include the following:

- Short preparation time

- Quick and easy to place (good workability)

- Short cure time

- Adhesiveness

- Cohesiveness

- Resistance to softening and flow

- Flexibility

- Elasticity

\section{MATERIAL AND TESTS}

Currently, the most commonly used polymer for bitumen modification is the styrene-butadiene-styrene (SBS) followed by other polymers such as styrene butadiene rubber (SBR), ethylene vinyl acetate (EVA) and polyethylene. The additive we short listed from the literature review is the polymer Styrene Butadiene Styrene(SBS).

SBS block copolymers are classified as elastomers that increase the elasticity of bitumen and they are probably the most appropriate polymers for bitumen modification. Following are the key characteristics or advantages of SBS and the reason why we chose SBS as our additive.

1. High Elastic Response

2. Resist Permanent deformation by stretching and recovering their initial shape.
3. Increased tensile strength with elongation and have the ability to recover to the initial condition after an applied load is removed.

4. It reduces the working temperature and to have a considerable elongation.

Although low temperature flexibility is increased, some authors claim that a decrease in strength and resistance to penetration is observed at higher temperatures.SBS copolymers derive their strength and elasticity from physical and cross linking of the molecules into a three-dimensional network. When SBS is blended with bitumen, the elastomeric phase of the SBS copolymer absorbs the oil fractions from the bitumen and swells up to nine times as much as its initial volume. At suitable SBS concentration, a continuous polymer phase is formed throughout the polymer modified bitumen (PMB) and significantly modifies the base bitumen properties.

Polymers are usually provided in the form of pellets or powder which can be subsequently diluted to the required polymer content by blending with base bitumen by using low to high shear mixer. Blending pellets of with base bitumen results in a special polymer concentration suitable for different applications.

The SBS polymer used was SBS-GP-4000. SBS-DP4000 is a linear SBS Polymer in powder form that consist of Styrene content $30 \%$ by weight and Butadiene content $70 \%$ by weight. Other different characteristics of the polymer are as given below ,

\section{TableI. Properties of SBS}

\begin{tabular}{|l|l|l|l|l|}
\hline $\begin{array}{l}\text { Polymer } \\
\text { Properties }\end{array}$ & $\begin{array}{l}\text { Unit } \\
\text { Measure }\end{array}$ & $\begin{array}{l}\text { Typical } \\
\text { Value }\end{array}$ & Range & $\begin{array}{l}\text { Referred } \\
\text { Standard }\end{array}$ \\
\hline $\begin{array}{l}\text { Specific } \\
\text { Gravity }\end{array}$ & g/cc & 0.94 & N/A & $\begin{array}{l}\text { ASTM D } \\
792\end{array}$ \\
\hline $\begin{array}{l}\text { Volatile } \\
\text { Matter }\end{array}$ & $\%$ & 0.2 & 1.0 max & $\begin{array}{l}\text { ASTM D } \\
1416\end{array}$ \\
\hline Ash Content & $\%$ & 0.1 & $6.0 \max$ & $\begin{array}{l}\text { ASTM D } \\
1416\end{array}$ \\
\hline $\begin{array}{l}\text { Bound } \\
\text { Styrene }\end{array}$ & $\%$ & 32 & $28-35$ & $\begin{array}{l}\text { ASTM D } \\
1416\end{array}$ \\
\hline $\begin{array}{l}\text { Shore A } \\
\text { Hardness }\end{array}$ & Sh A & 78 & N/A & $\begin{array}{l}\text { ASTM D } \\
2240\end{array}$ \\
\hline $\begin{array}{l}\text { Brookfield } \\
\text { Viscosity (A) }\end{array}$ & cps & 11,500 & $\begin{array}{l}10- \\
13,000\end{array}$ & $\begin{array}{l}\text { ASTM D } \\
1084\end{array}$ \\
\hline $\begin{array}{l}\text { Molecular } \\
\text { Weight }\end{array}$ & Daltons & 180 & $170-190$ & \\
\hline
\end{tabular}

A 50/70 penetration grade base (unmodified) bitumen has been used for the study. In order to characterize the properties of the base bitumen, conventional test methods such as; penetration test, softening point test, ductility test, etc. were performed. To check the characteristics of the aggregate used in the study we are going to perform tests like impact value test, abrasion value test, shape test, specific gravity test. These tests were conducted in conformity with the relevant test methods that are presented in Table. 
TableII. Different Tests Performed

\begin{tabular}{|c|c|}
\hline Test & IS CODE \\
\hline Marshal Stability Test & ASTM D6927 \\
\hline Viscosity Test & IS : 1206-1978 \\
\hline Ductility Test & IS : 1208 - 1978 \\
\hline Penetration Test & IS: $1203-1978$ \\
\hline Softening Point Test & IS : 1205-1978 \\
\hline Impact Value Test & IS 2386 \\
\hline Shape test & IS 2386 \\
\hline Abrasion Value test & IS 2386 \\
\hline Specific gravity test & IS 2386 \\
\hline
\end{tabular}

Also to find out the specific quantity of the bitumen and the additive we will perform marshal test on both samples, with and without additive sample.

\section{TEST AND RESULT}

\section{A. Softening Point Test}

Bitumen does not suddenly change from solid to liquid state, but as the temperature increases, it gradually becomes softer until it flows readily. All semi-solid state bitumen grades need sufficient fluidity before they are used for application with the aggregate mix. For this purpose, bitumen is sometimes cut back with solvent like kerosene. The common procedure however is to liquefy the bitumen by heating. The softening point is the temperature at which the substance attains particular degree of softening under specified condition of test. For bitumen, it is usually determined by Ring and Ball Test. It is obvious that harder grade bitumen possess higher softening point than softer grade bitumen. The results are shown in Table.

TableIII. Results of Softening Point Test

\begin{tabular}{|c|c|c|c|c|}
\hline Sr. & Type & Sample1 & Sample2 & Avg. \\
\hline 1. & Conventional & 48.5 & 50 & 49.2 \\
\hline 2. & Bitumen+2\% SBS & 50.5 & 52.5 & 51.5 \\
\hline 3. & Bitumen+4\% SBS & 56 & 58.6 & 57.3 \\
\hline 4. & Bitumen+6\% SBS & 69 & 68 & 68.5 \\
\hline
\end{tabular}

\section{B. Penetration Test}

Bituminous materials are available in various types and grades. The penetration test determines the hardness of these materials by measuring the depth in tenth of a milSBSter to which a standard needle will penetrate vertically under specified conditions of standard load, time and temperature. The sample is maintained at the standard temperature of 25 ${ }^{\circ} \mathrm{C}$. The total load on needle is $100 \mathrm{gm}$. The softer the bitumen, the greater will be its number of penetration unit. The results are shown in Table,

TableIV. Results of Penetration Test

\begin{tabular}{|c|c|c|c|c|c|}
\hline Sr. & Type & Trial1 & Trial2 & Trial3 & Avg. \\
\hline 1. & Conventional & 64 & 62 & 62 & 63 \\
\hline 2. & Bitumen+2\% SBS & 59 & 61 & 62 & 61 \\
\hline 3. & Bitumen+4\% SBS & 50 & 48 & 52 & 50 \\
\hline 4. & Bitumen+6\% SBS & 47 & 50 & 49 & 49 \\
\hline
\end{tabular}

\section{Ductility Test}

In the flexible pavement construction where bitumen binders are used, it is of significant importance that the binders form ductile thin films around the aggregates. This serves as a satisfactory' binder in improving the physical interlocking of the aggregates. The binder material which does not possess sufficient ductility would crack and thus provides previous pavement surface. The results are shown in Table .

TableV. Results of Ductility Test

\begin{tabular}{|c|c|c|c|c|}
\hline Sr. & Type & Sample1 & Sample2 & Avg. \\
\hline 1. & Conventional & 86 & 82 & 84 \\
\hline 2. & Bitumen+2\% SBS & 78 & 87 & 82.5 \\
\hline 3. & Bitumen+4\% SBS & 55 & 64 & 59.5 \\
\hline 4. & Bitumen+6\% SBS & 49 & 59 & 54 \\
\hline
\end{tabular}

\section{Impact Value Test}

To determine the impact value of given sample using Aggregate Impact Testing Machine. Toughness is the property of a material to resist impact. Due to traffic loads the road stone are subjected to the pounding action of impact and there is possibility of breaking into smaller pieces. The road stone should therefore be tough enough to resists fracture under impact. A test designed to evaluate the toughness of stones i.e. the resistance of the stones to fracture under repeated impacts may be called an impact test for road stones. The test sample shall consist of aggregate passing through $12.5 \mathrm{~mm}$ IS sieve and retained on a $10 \mathrm{~mm}$ IS sieve. Test aggregates are filled up to about one third full in the cylindrical measure and tamped 25 times with rounded end of the tamping rod. The hammer is raised until its lower face is $38 \mathrm{~cm}$ above the upper surface of the aggregates in the cup, and allowed to fall freely on the aggregates. The test sample is subjected to a total of 15 such blows, each being delivered at an interval of not less than one second. And then weight of test sample is taken and further calculation had been done. The results are shown in Table.

TableVI. Results of Impact value Test

\begin{tabular}{|c|c|c|c|}
\hline Sr.no. & A.I.V & \multirow{2}{*}{ Avg. } & Remark \\
\cline { 1 - 2 } 1. & 9.57 & $\mathbf{1 0 . 3 2} \%$ & \multirow{2}{*}{ STRONG } \\
\cline { 1 - 2 } 2. & 11.07 & & \\
\hline
\end{tabular}

\section{E. Shape test}

To determine the value of Flakiness and Elongation Indices of Coarse aggregates. The particle shape of aggregates is determined by the percentages of flaky and elongated particles contained in it. In the case of gravel it is determined by its angularity number. For base course and construction of bituminous and cement concrete types, the presence of flaky and elongated particles are considered undesirable as they may cause inherent weakness with possibilities of breaking down under heavy loads. Rounded aggregates are preferred in cement concrete road construction as the workability of concrete improves. Angular shape of particles is desirable for granular base course due to increased stability derived from the better interlocking. Thus evaluation of shape of the 
particles, particularly with reference to flakiness, elongation and angularity is necessary. The results are shown in Table .

TableVII. Results of Shape Test

\begin{tabular}{|c|c|c|c|}
\hline$\dot{z}$ & 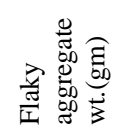 & 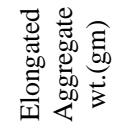 & 死 \\
\hline $\begin{array}{l}\text { Combine } \\
\text { Index }\end{array}$ & $15.49 \%$ & $13.65 \%$ & $29.16 \%$ \\
\hline
\end{tabular}

\section{F. Abrasion Value test}

To determine the hardness of the sample aggregate by testing for abrasion value using Los Angles Testing Machine. Due to the movement of traffic, the road stones are used in the surfacing course are subjected to wearing action. At the top Resistance to wear or hardness is hence an essential property of road aggregate, especially when used in wearing course. Thus road stones should be hard enough to resist the abrasion due the traffic. When fast moving traffic fitted with pneumatic tyres move on the road, the road particles present between the wheel and road surface causes abrasion on the road stone. Steel tyres of the animal drawn vehicles which rub against the stones can cause considerable abrasion of the stones on the road surface Hence in order to tests are carried out in the laboratory. The results are shown in Table.

TableVIII. Results of Abrasion value Test

\begin{tabular}{|c|c|c|c|}
\hline Sr.No. & $\%$ wear & Avg. & $\begin{array}{c}\text { max permissible } \\
\text { value (30\%) }\end{array}$ \\
\cline { 1 - 2 } 1. & $15.88 \%$ & & Ok \\
\cline { 1 - 2 } 2. & $16.22 \%$ & $16.05 \%$ & \\
\hline
\end{tabular}

\section{G. Marshall Stability Test}

The Marshall Stability and flow test provides the performance prediction measure for the Marshall Mix design method. The stability portion of the test measures the maximum load supported by the test specimen at a loading rate of $50.8 \mathrm{~mm} / \mathrm{minute}$. Load is applied to the specimen till failure, and the maximum load is designated as stability. During the loading, an attached dial gauge measures the specimen's plastic flow (deformation) due to the loading. The flow value is recorded in $0.25 \mathrm{~mm}(0.01$ inch) increments at the same time when the maximum load is recorded. Standard temperature $600^{\circ} \mathrm{C}$ corresponding load carried by specimen is called Marshal Stability value and the deformation at failure in units of $0.25 \mathrm{~mm}$ is recorded as Marshal flow value. The setup is shown in figure 1 .

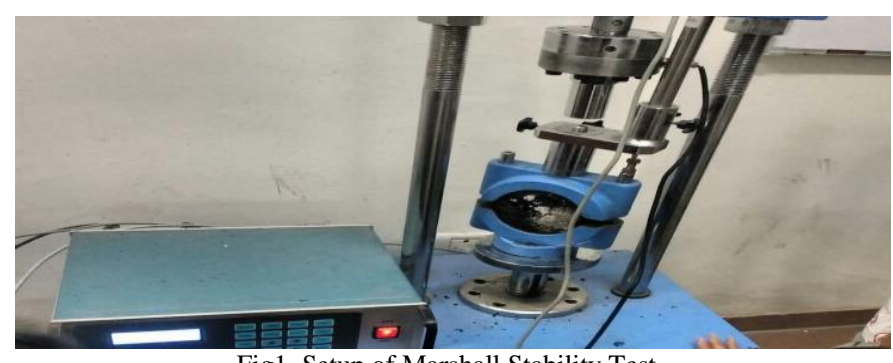

Fig1. Setup of Marshall Stability Test

For the top surface layer Bituminous Concrete (BC) Grade 1 is considered as per MORTH. Based on trials of blending the gradation is set. The gradation curve is shown in Figure 2.

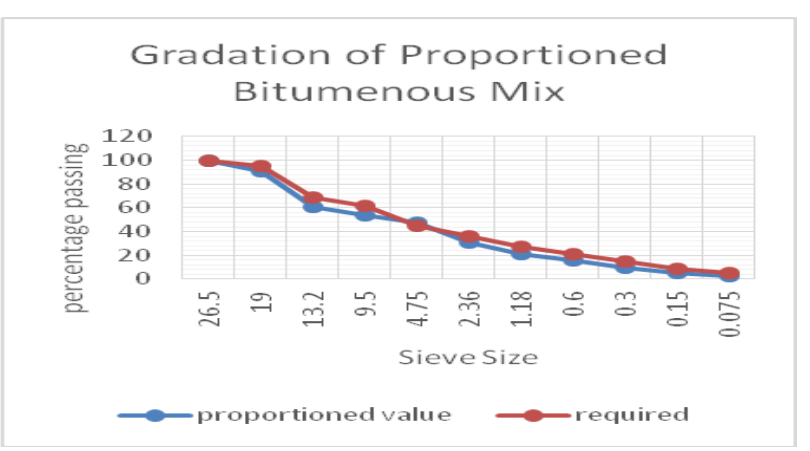

Fig2. Gradation of Proportioned Bituminous Mix

As per the procedure we have performed the tests and following are the result we get for the Marshall mix,

Table IX. Bituminous Mix Test Results

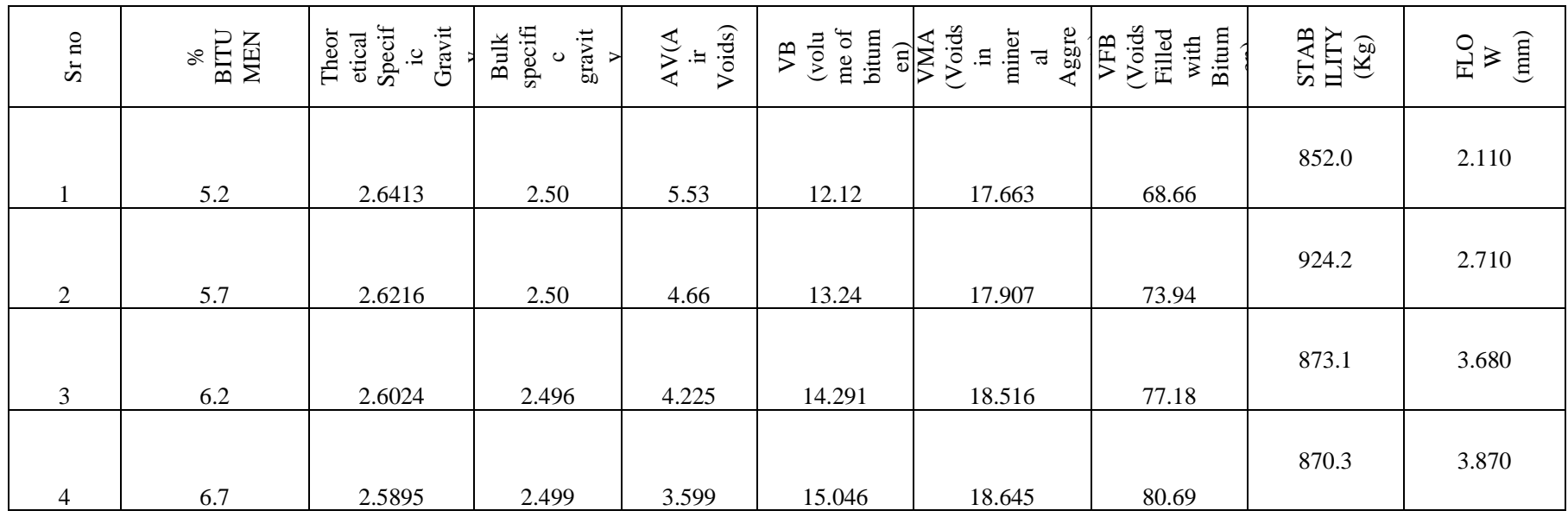


- Graphs for \% Bitumen

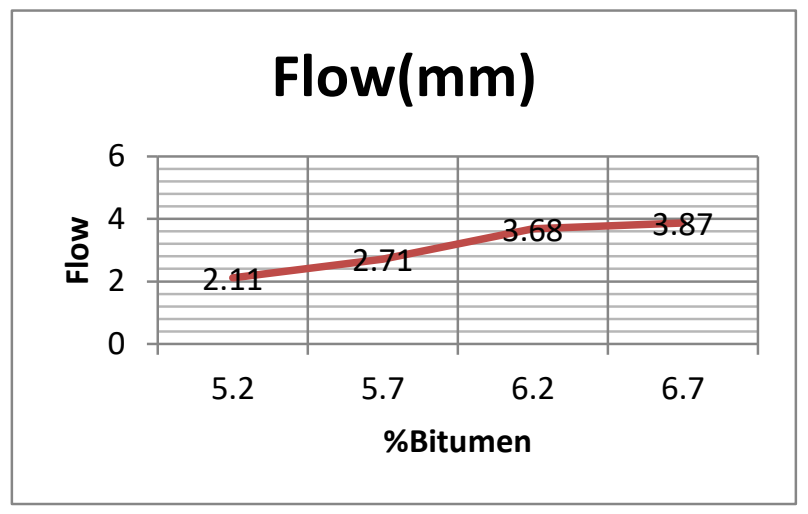

Varaition of Flow with \% Bitumen

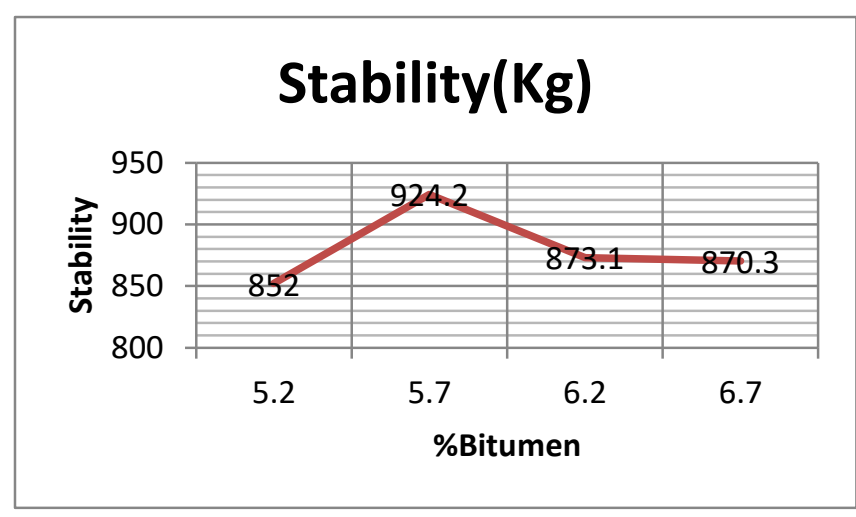

Varaition of Stability with \% Bitumen

Fig 3. Flow and Stability value of the mix

\section{- Optimum Bitumen Content}

Table X. Optimum Bitumen Content
\begin{tabular}{|c|c|c|c|}
\hline $\begin{array}{c}\text { Sr. } \\
\text { no }\end{array}$ & Properties & Value & Bitumen $(\%)$ \\
\hline 1 & $\begin{array}{c}\text { Max } \\
\text { Stability(KN) }\end{array}$ & 11.44 & 5.7 \\
\hline 2 & $\begin{array}{c}\text { min flow } \\
(\mathrm{mm})\end{array}$ & 2.11 & 5.2 \\
\hline 3 & AV & $4 \%$ & 6.3 \\
\hline 4 & Max. Gm & 2.504 & 5.7 \\
\hline & OBC & & $5.7 \%$ \\
\hline
\end{tabular}

H. Optimum SBS Content: -

TableXI. Marshall results for the improved mix

\begin{tabular}{|c|c|c|c|c|c|c|c|c|c|}
\hline $\begin{array}{l}\stackrel{0}{\leftrightarrows} \\
\dot{\tilde{\omega}}\end{array}$ & $\begin{array}{l}\partial^{0} \\
\infty \\
\tilde{n}\end{array}$ & 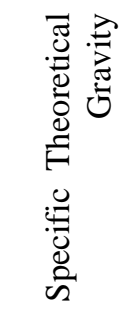 & 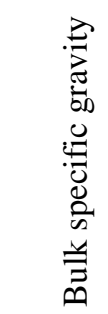 & 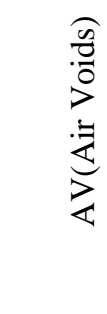 & 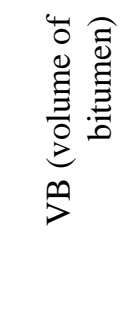 & 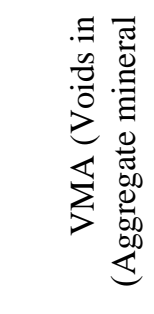 & 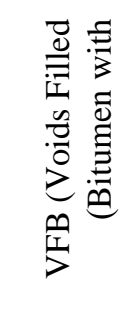 & 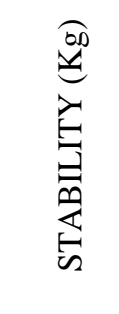 & 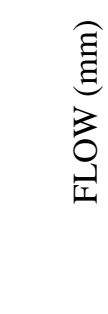 \\
\hline 1 & 2 & 2.625 & 2.500 & 4.986 & 13.097 & 18.083 & 72.426 & 930.4 & 2.07 \\
\hline 2 & 4 & 2.621 & 2.504 & 4.699 & 13.346 & 18.045 & 73.959 & 1217.2 & 2.54 \\
\hline 3 & 6 & 2.619 & 2.504 & 4.610 & 13.513 & 18.123 & 74.565 & 1108.7 & 3.41 \\
\hline 4 & 7 & 2.615 & 2.511 & 4.117 & 13.738 & 17.854 & 76.943 & 1092.2 & 3.87 \\
\hline
\end{tabular}




\section{- Graphs For SBS \%}

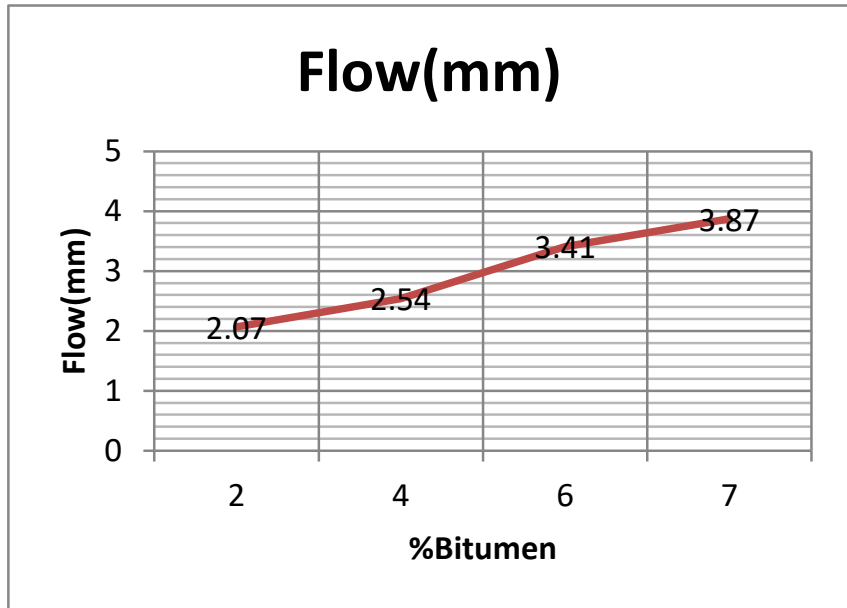

Varaition of Flow with \% SBS

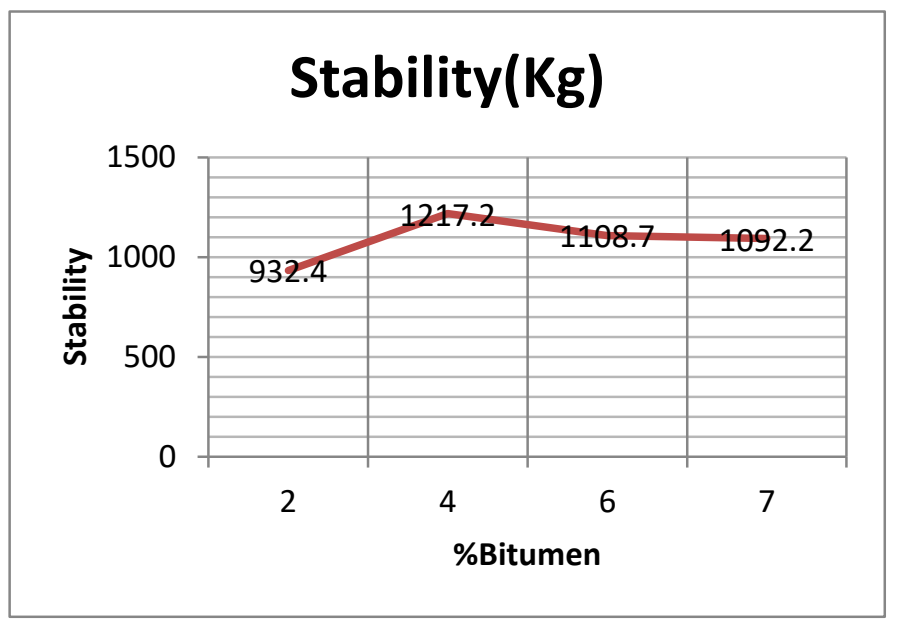

Varaition of Stability with \% SBS

Fig.4 Flow and Stability Value for the improved mix

\section{H1. Optimum Additive Content}

Table XII. Optimum Additive Conetent

\begin{tabular}{|c|c|c|c|}
\hline Sr. no & Properties & Value & SBS(\%) \\
\hline 1 & Max Stability $(\mathrm{KN})$ & 12.1 & 4 \\
\hline 2 & min flow $(\mathrm{mm})$ & 2.07 & 2 \\
\hline 3 & AV & $4.1 \%$ & 7 \\
\hline 4 & Max. Gm & 2.511 & 7 \\
\hline & Optimum & & $\mathbf{5 \%}$ \\
\hline
\end{tabular}

\section{SUMMARY AND CONCLUSION}

- After performing the test following remarks are made: -

Optimum Bitumen Content for the sample $=5.7 \%$ Optimum SBS Content at 5.7\% Bitumen Content $=$ $5 \%$

- Advantages of using SBS: -

From the above results, we can say that SBS can be used as a additive in bitumen as it increases the stability of the asphalt mix, which shows that it can sustain more load. Apart from this, SBS is cheaper, easily available and can be used directly without any pre-processing.

- In this study, attempt has been made to assess the properties of modified bitumen by addition of SBS. From the test results, it is observed that the addition of SBS indicates positive changes on properties of bitumen, i.e. SBS has a possibility to be used as an additive in bitumen for the improvement of the conventional mix.

\section{Future scope for study: -}

- Further study can consider determination of stability results and determination of optimum binder content by using Marshall Apparatus and studying different properties of bitumen by adding different materials like GGBFS, Metal curls, Sasobit etc.

- Further, based on laboratory results the mix can be implemented in field conditions and observations can be made on the overall behaviour of mix i.e. durability, water susceptibility, load bearing capacity etc. due to environmental effects and traffic loading.

\section{REFERENCES}

[1] Ala Abbas, Umme Amina Mannan, and Samer Dessouky (2013) "Effect of recycled asphalt shingles on physical and chemical properties of virgin asphalt binders", Construction and Building Materials 45 (2013) 162-172

[2] CAI Xu, ZHU Feng-dan, WANG Duan-yi, WU Kuang-huai, and YANG Guo-liang (2016), "Design of a Rut-resistant Asphalt Mixture Using the Simplified Multilevel Mixing Method", Journal of Highway and Transportation, Research and Developement, 10(4)

[3] Didier Lesueura, Joëlle Petitb and Hans-Josef Ritterc (2012)," The mechanisms of hydrated SBS modification of asphalt mixtures: a state-of-the-art review", Road Materials and Pavement Design, 2013 Vol. 14, No. 1, 1-16.

[4] IS:1203 (1978). "Determination Of Penetration Value Of Bitumen", Bureau of Indian Standard, New Delhi.

[5] IS:1205 (1978). "Determination Of Softening Point Of Bitumen", Bureau of Indian Standard, New Delhi.

[6] IS:1208 (1978). "Determination Of Ductility Of Bitumen", Bureau of Indian Standard, New Delhi.

[7] IS:2386 Part-I (1963). "Determination Of Flakiness And Elongation Indices Of Coarse Aggregate", Bureau of Indian Standard, New Delhi.

[8] IS:2386 Part-III (1963). "Determination Of Specific Gravity And Water Absobtion Test For Aggregates", Bureau of Indian Standard New Delhi.

[9] IS:2386 Part-IV (1963). "Determination Of Aggregate Impact Value", Bureau of Indian Standard, New Delhi.

[10] IS:2386 Part-V (1963). "Determination Of Abbrasion Value Of Road Aggregate", Bureau of Indian Standard, New Delhi.

[11] Jizhe Zhang, Gordon D.Airey, JamesGrenfell, AlexK.Apeagyei, and MartynBarrett (2016) "Development of a composite substrate pee test to asses moisture sensitivity of aggregate-bitumen bonds" International Journal of Adhesion \& Adhesives 68 (2016) 133-141

[12] Kelly L. Smith, A. and Russell Romine (1993), "Materials and Procedures for Sealing and Filling Cracks in Asphalt-Surfaced Pavements", Strategic Highway Research Program National Research Council 348

[13] Lawrence Zanko, David M. and Hopstock, (2016), "Evaluate and Develop Innovative Pavement Repair and Patching: Taconite-Based Repair Options", Minnesota Department of Transportation Research Services \& Library 395 John Ireland Boulevard, MS 330 St. Paul, Minnesota 55155-1899 
[14] Mahyar Arabani, and Seyed Amid Tahami (2017) "Assessment of mechanical properties of rice husk ash modified asphalt mixture", Construction and Building Materials 149 (2017) 350-358

[15] Mohd Ezree Abdullah, and Kemas Ahmad Zamhari, (2016) "Engineering properties of asphalt binders containing nanoclay and chemical warm-mix asphalt additives", Construction and Building Materials 112 (2016) 232-240

[16] Nyoman Arya Thanaya, and Nyoman Widana Negara (2014) "Properties of Cold AsphaltEmulsion Mixtures (CAEMs) using materials from old road pavement milling" 2nd International Conference on Sustainable Civil Engineering Structures and Construction Materials Procedia Engineering 95 (2014) 479 - 488

[17] Obaidi, H., and Gomez-Meijide B. (2017) "A fast pothole repair method using asphalt tiles and induction heating" Construction and Building Materials 131 (2017) 592-599

[18] Rebecca S. and McDaniel Jan Olek (2014) "Pavement Patching Practices A Synthesis of Highway Practice", National cooperative highway research program synthesis 463

[19] Shifeng Wang, Dingxin Cheng, and Feipeng Xiao (2017)" Recent developments in the application of chemical approaches to rubberized asphalt" Construction and Building Materials 131 (2017) 101-113

[20] Somesh Jethwani, Shubham Ashish Jha , and Dheeraj Sangtiani(2017)" Utilization \& Specification of Plastic Waste in Bituminous Roads" International Journal of Engineering Research Volume No.6, Issue No.2, pp :91-94

[21] Umme Amina Mannan, Mohiuddin Ahmad, Rafiqul A. and Tarefder(2017) "Influence of moisture conditioning on healing of asphalt binders" Construction and Building Materials 146 (2017) 360-369

[22] Yuming Yang, Zhendong Qian, and Xin Song (2015) "A pothole patching material for epoxy asphalt pavement on steel bridges: Fatigue test and numerical analysis", Construction and Building Materials 94 (2015) 299-305J. Clerk Maxwell, A Treatise on Electricity and Magnetism, 3rd ed., vol. 2. Oxford: Clarendon, 1892, pp.68-73 